\title{
Política de segurança pública no Brasil: avanços, limites e desafios
}

\author{
Vilobaldo Adelídio de Carvalho \\ Universidade Federal do Piauí (UFPI)
}

\author{
Maria do Rosário de Fátima e Silva \\ Universidade Federal do Piauí (UFPI)
}

\section{Política de segurança pública no Brasil: avanços, limites e desafios}

Resumo: O presente artigo, elaborado por meio de pesquisa teórica, discute a política de segurança pública adotada no Brasil contemporâneo, especialmente nesta primeira década no século 21. Inicialmente, apresenta reflexões sobre o papel do Estado no sentido de garantir a segurança pública enquanto direito fundamental do cidadão. Posteriormente, destaca o Plano Nacional de Segurança Pública (PNSP) e o Programa Nacional de Segurança Pública com Cidadania (Pronasci) como inovações na política de segurança pública brasileira. Considera que, apesar dos limites e desafios próprios da complexidade relativa à questão, têm ocorrido avanços na democratização da política de segurança, por meio de uma maior participação da sociedade nas discussões e na implementação das ações nessa área. Palavras-chave: Estado. Política pública. Segurança pública. Brasil.

\section{Public Safety Policy in Brazil: Advances, Limits and Challenges}

Abstract: This article, based on theoretical research, discusses public safety policies adopted in contemporary Brazil, particularly in the first decade of the $21^{\text {st }}$ century. It initially reflects on the role of the state to guarantee public safety as a fundamental right of the citizen. It then highlights the National Public Safety Plan (PNSP) and the National Public Safety with Citizenship Program (Pronasci) as an innovation in Brazilian public safety policy. It considers that despite the limits and challenges related to the complexity of the issue, advances have occurred in the democratization of public safety policy, by means of greater participation of society in the discussions and implementations of actions in this field.

Key words: State. Public policy. Public safety. Brazil. 


\section{Introdução}

O sistema político, surgido na modernidade, e que predomina nos governos contemporâneos, demonstra que o papel das organizações políticas, primordialmente o do Estado, tem sido reestruturado para atender ao movimento dinâmico da sociedade. Demonstra, também, a consolidação do processo civilizacional, em curso neste século 21, que impõe a necessidade de segurança como garantia do exercício da cidadania.

Nesse contexto, pretende-se caracterizar a sociedade como uma teia de relações em constante movimento de continuidades e rupturas, engendradas pela própria dinâmica do processo contraditório que sustenta a (re)produção do sistema capitalista, tendo o Estado papel crucial no controle social, pela via de mecanismos jurídicos e aparatos institucionais. Por outro lado, considera-se a segurança pública um processo articulado, caracterizando-se pelo envolvimento de interdependência institucional e social, enquanto a política de segurança pública pode ser definida como a forma de instituir mecanismos e estratégias de controle social e enfrentamento da violência e da criminalidade, racionalizando as ferramentas da punição (ADORNO, 1996; BENGOCHEA et al., 2004; SAPORI, 2007).

A segurança da sociedade surge como o principal requisito à garantia de direitos e ao cumprimento de deveres, estabelecidos nos ordenamentos jurídicos. A segurança pública é considerada uma demanda social que necessita de estruturas estatais e demais organizações da sociedade para ser efetivada. Às instituições ou órgãos estatais, incumbidos de adotar ações voltadas para garantir a segurança da sociedade, denomina-se sistema de segurança pública, tendo como eixo político estratégico a política de segurança pública, ou seja, o conjunto de ações delineadas em planos e programas e implementados como forma de garantir a segurança individual e coletiva.

O início deste século 21 tem sido marcado, principalmente, pelo processo de globalização econômico-financeira, impelindo à redefinição do papel do Estado na gestão pública e na sua relação com o mercado e com a sociedade. Nesse processo, a gestão da política de segurança pública, como suporte para enfrentamento da violência e da criminalidade, representa um desafio tanto para o Estado quanto para a sociedade.

A questão da segurança pública tem despertado o interesse de diversos estudiosos, da sociedade e dos governos. Os instrumentos de enfrentamento da criminalidade e da violência têm sido insuficientes para proporcionar a segurança individual e coletiva. No âmbito do processo de constituição da política de segurança pública, são elaborados os mecanismos e as estratégias de enfrentamento da violência e da criminalidade que afeta o meio social. A participação da sociedade por meio de suas instituições representativas torna-se crucial para o delineamento de qualquer política pública. A complexidade da questão implica na necessidade de efetiva participação social, como forma de democratizar o aparelho estatal no sentido de garantia de uma segurança cidadã.

Este artigo tem como objetivo debater a política de segurança pública no Brasil, especialmente sua configuração nesta primeira década do século 21. Parte de algumas reflexões acerca do papel do Estado na garantia da segurança pública, enquanto direito básico ao exercício da cidadania, para, em seguida, traçar algumas considerações acerca do Plano Nacional de Segurança Pública (PNSP), implementado a partir do ano 2000, e do Programa Nacional de Segurança Pública com Cidadania (Pronasci), estruturado em 2007, e ainda em execução, ambos de iniciativa do Governo Federal.

\section{Estado e a política de segurança pública no Brasil contemporâneo}

O contexto contemporâneo, caracterizado pela globalização, principalmente no âmbito econômico, tem provocado transformações na estrutura do Estado e redefinição de seu papel enquanto organização política. Diferentemente da redução do papel do Estado no âmbito econômico e social, no que se refere à segurança pública, tem ocorrido uma ampliação dos instrumentos de controle sobre a sociedade. Por isso, "[...] não tardou para que no final do século 20, na sociedade de controle, com o neoliberalismo, aparecesse uma terceira versão para os perigosos a serem confinados [...]" (PASSETTI, 2003, p. 134).

$\mathrm{Na}$ esfera do "Estado neoliberal", surge o "Estado penal", pela via de ações fortalecedoras do controle dos processos de marginalização econômica e social:

[...] por Estado penalizador, os estudos e pesquisas procuram mostrar as dimensões atuais dos efeitos da globalização nas segregações, confinamentos e extermínios de populações pobres, adulta, juvenil e infantil (PASSETTI, 2003, p. 170).

Esse processo de "criminalização da pobreza e da miséria" está diretamente relacionado à "[...] insegurança social gerada em toda parte pela dessocialização do trabalho assalariado, o recuo das proteções coletivas e a 'mercantilização' das relações humanas" (WACQUANT, 2001, p. 13). Portanto, a ascensão do "Estado penal" decorre da deterioração das relações sociais de produção e da precarização das formas de trabalho, impostas pelo "Estado neoliberal", implantado para atender aos ditames do mercado, pois: 
Em tais condições, desenvolver o Estado penal para responder às desordens suscitadas pela desregulamentação da economia, pela dessocialização do trabalho assalariado e pela pauperização relativa e absoluta de amplos contingentes do proletariado urbano, aumentando os meios, a amplitude e a intensidade da intervenção do aparelho policial e judiciário, equivale a (r)estabelecer uma verdadeira 'ditadura sobre os pobres’ (WACQUANT, 2001, p. 10).

Nessa situação, a potencialização do mercado, como instrumento regulador das relações sociais em detrimento ao Estado, ocorre concomitantemente ao contingenciamento dos mecanismos de assistência social e ao processo de fortalecimento da penalização como forma de ampliar o controle sobre as periferias e assegurar a manutenção das relações de poder.

Com efeito, acaba-se tendo "menos Estado" para os ricos, para possibilitar a multiplicação do lucro pela via do mercado e, "mais controle" para os pobres, seja por meio do "Estado penalizador" e "assistencial" ou do processo de exclusão próprio do mercado. Os governos, ao adotarem ações de repressão à criminalidade por meio da institucionalização de processos de criminalização de segmentos sociais, excluídos das possibilidades oferecidas pelo mercado, como forma de dar respostas aos anseios da sociedade em geral, contribuem para que o papel do Estado sirva aos poucos "donos do poder" em detrimento da soberania do povo.

Estamos diante de um processo contraditório no que se refere ao papel do Estado. Temos, assim, um "Estado para os pobres", com menos assistência e mais controle e vigilância e um "Estado para os ricos", que possibilita menos controle sobre a reprodução econômica. Com isso, as formas de penalização são direcionadas a sujeitos diferenciados.

No Brasil, o processo de democratização do Estado, após duas décadas de ditadura militar, pouco modificou o Estado penalizador, fundado na institucionalização da criminalização. No aspecto teórico, constitucional, tem-se um Estado democrático. Porém, no campo prático, ainda se vive em um Estado autoritário, principalmente nas questões relacionadas à segurança pública, pois,

No Brasil, a reconstrução da sociedade e do Estado democráticos, após 20 anos do regime autoritário, não foi suficientemente profunda para conter o arbítrio das agências responsáveis pelo controle da ordem pública. Não obstante as mudanças dos padrões emergentes de criminalidade urbana violenta, as políticas de segurança e justiça criminal, formuladas e implementadas pelos governos democráticos, não se diferenciaram grosso modo daquelas adotadas pelo regime autoritário. A despeito dos avanços e conquistas obtidos nos últimos anos, traços do passado autoritário revelam-se resistentes às mudanças em direção ao Estado democrático de Direito [...] (ADORNO, 1996, p. 233).

O processo de transição para a democracia, das últimas décadas, enfrentou o desafio de manter a ordem pública em um contexto afetado pela insegurança urbana e a necessidade de mudança de atuação dos órgãos de segurança pública, estruturados sob a influência de resquícios autoritários, mas com a responsabilidade de atuar de acordo com os princípios democráticos, impostos pela sociedade por meio dos movimentos sociais.

A "Constituição Cidadã", promulgada no Brasil em 1988, não culminou, concomitantemente, na construção de uma política de segurança pública democrática por parte dos órgãos responsáveis, estabelecidos no "Estado democrático de Direito". Por isso, as ações de "controle da ordem pública" tornaramse mais complexas na "ordem democrática" e a reorganização do aparelho estatal não resultou na imediata participação social na construção da política de segurança pública, necessária ao país.

Estado e sociedade devem exercer papéis cruciais na definição de estratégias políticas e de poder que legitimam o processo pelo qual se desenvolve a política pública. Neste embate, os interesses e as contradições, inerentes à dinâmica das relações entre governantes e governados, constituem o fundamento da construção política.

\footnotetext{
Trata-se, pois, a política pública, de uma estratégia de ação, pensada, planejada e avaliada, guiada por uma racionalidade coletiva na qual tanto o Estado como a sociedade desempenham papéis ativos. Eis porque o estudo da política pública é também o estudo do Estado em ação (Meny e Toenig) nas suas permanentes relações de reciprocidade e antagonismo com a sociedade, a qual constitui o espaço privilegiado das classes sociais (Ianni) (PEREIRA, 2009, p. 96).
}

Isto significa que a organização da sociedade por meio de instituições representativas possibilita um maior poder de pressão perante o Estado para que ocorra o atendimento de demandas construídas pela própria sociedade. Logicamente, subjacentes ao ato político que institui a política, existem relações de poder que indicam a correlação de forças sociais e políticas e o arranjo institucional delineador da política pública.

As políticas públicas, promovidas pelo Estado brasileiro até o início dos anos 1980, caracterizavam-se pela " $[\ldots .$.$] centralização decisória e financeira na es-$ fera federal [...], pela fragmentação institucional [...], pelo caráter setorial [...]" e, principalmente, pela “[...] exclusão da sociedade civil do processo de formulação das políticas, da implementação dos programas 
e do controle da ação governamental [...]" (FARAH, 2006, p. 189-90).

Nas políticas sociais, a complexidade da política de segurança pública envolve diversas instâncias governamentais e os três poderes da república. Cabe ao Poder Executivo o planejamento e a gestão de políticas de segurança pública que visem à prevenção e à repressão da criminalidade e da violência e à execução penal; ao Poder Judiciário cabe assegurar a tramitação processual e a aplicação da legislação vigente; e compete ao Poder Legislativo estabelecer ordenamentos jurídicos, imprescindíveis ao funcionamento adequado do sistema de justiça criminal.

O sistema de segurança pública brasileiro em vigor, desenvolvido a partir da Constituição Federal de 1988, estabeleceu um compromisso legal com a segurança individual e coletiva. Entretanto, no Brasil, em regra, as políticas de segurança pública têm servido apenas de paliativo a situações emergenciais, sendo deslocadas da realidade social, desprovidas de perenidade, consistência e articulação horizontal e setorial.

\begin{abstract}
Planejamento, monitoramento, avaliação de resultados, gasto eficiente dos recursos financeiros não têm sido procedimentos usuais nas ações de combate à criminalidade, seja no executivo federal, seja nos executivos estaduais. Desse ponto de vista, a história das políticas de segurança pública na sociedade brasileira nas duas últimas décadas se resume a uma série de intervenções governamentais espasmódicas, meramente reativas, voltadas para a solução imediata de crises que assolam a ordem pública [...] (SAPORI, 2007, p. 109).
\end{abstract}

Mecanismos essenciais não têm sido utilizados pelos diversos governos para possibilitar o pensar, o implementar, o implantar, o efetivar, com eficácia e eficiência, uma política de segurança pública como instrumento do Estado e da sociedade. A promulgação de leis, decretos, portarias e resoluções, visando instrumentalizar o enfretamento da criminalidade e da violência, sem que haja articulação das ações de segurança pública no contexto social, acaba apresentando resultados inconsistentes e insatisfatórios.

A atuação dos órgãos da segurança pública requer interação, sinergia de ações combinadas a medidas de participação e inclusão social e comunitária, cabendo ao Estado o papel de garantir o pleno funcionamento dessas instituições, tendo em vista que:

A segurança pública é um processo sistêmico e otimizado que envolve um conjunto de ações públicas e comunitárias, visando assegurar a proteção do indivíduo e da coletividade e a ampliação da justiça da punição, recuperação e tratamento dos que violam a lei, garantindo direitos e cidadania a todos. Um processo sistêmico porque envolve, num mesmo cenário, um conjunto de conhecimentos e ferramentas de competência dos poderes constituídos e ao alcance da comunidade organizada, interagindo e compartilhando visão, compromissos e objetivos comuns; e otimizado porque depende de decisões rápidas e de resultados imediatos (BENGOCHEA et al., 2004, p. 120).

Trata-se de uma questão significativamente complexa que impõe a necessidade de aproximação entre diversas instituições e sujeitos. Entende-se, portanto, a segurança pública como um processo articulado e dinâmico que envolve o ciclo burocrático do sistema de justiça criminal. Sem articulação entre polícias, prisões e judiciário, inclusive sem o envolvimento da sociedade organizada, não existe eficácia e eficiência nas ações de controle da criminalidade e da violência e nas de promoção da pacificação social.

No Brasil, somente uma década após a promulgação da "Constituição Cidadã", que estabeleceu a segurança pública como "dever do Estado e responsabilidade de todos", a política de segurança pública passa a ser pensada sob o contexto de uma sociedade democraticamente organizada, pautada no respeito aos direitos humanos, em que o enfrentamento da criminalidade não significa a instituição da arbitrariedade, mas a adoção de procedimentos táticooperacionais e político-sociais que considerem a questão em sua complexidade. Nesse panorama, no ano 2000, é criado o Plano Nacional de Segurança Pública (PNSP), e no ano de 2007, o Programa Nacional de Segurança Pública com Cidadania (Pronasci), inovando a forma de abordar dessas questões.

\section{O Plano Nacional de Segurança Pública}

O governo Fernando Henrique Cardoso, tendo em vista os desdobramentos da Conferência Mundial de Direitos Humanos, ocorrida em Viena, em 1993, cria, em 1996, o Programa Nacional de Direitos Humanos (PNDH), aperfeiçoando-o em 2000, com a instituição do II Programa Nacional de Direitos Humanos, após a IV conferência Nacional de Direitos Humanos, ocorrida em 1999. Demonstrando disposição em reorganizar o arranjo e a gestão da segurança pública, o Governo Federal, cria, em 1995, no âmbito do Ministério da Justiça, a Secretaria de Planejamento de Ações Nacionais de Segurança Pública (Seplanseg), transformando-a, no ano de 1998, em Secretaria Nacional de Segurança Pública (Senasp), tendo como perspectiva atuar de forma articulada com os estados da federação para a implementação da política nacional de segurança pública.

A instituição da Senasp, como órgão executivo, significou a estruturação de mecanismos de gestão capazes de modificar o arranjo institucional da orga- 
nização administrativa da segurança pública no âmbito governamental federal. Surgiu, então, o Plano Nacional de Segurança Pública (PNSP), voltado para o enfrentamento da violência no país, especialmente em áreas com elevados índices de criminalidade, tendo como objetivo aperfeiçoar as ações dos órgãos de segurança pública.

O Plano Nacional de Segurança Pública de 2000 é considerado a primeira política nacional e democrática de segurança focada no estímulo à inovação tecnológica; alude ao aperfeiçoamento do sistema de segurança pública através da integração de políticas de segurança, sociais e ações comunitárias, com a qual se pretende a definição de uma nova segurança pública e, sobretudo, uma novidade em democracia (LOPES, 2009, p. 29).

Efetivamente, a inovação tecnológica é fundamental para que os instrumentos utilizados por parte dos operadores da segurança pública possam ser eficazes e eficientes. Neste aspecto, essa proposta do PNSP pode ser considerada extremamente estratégica.

O PNSP estabeleceu um marco teórico significativo na propositura da política de segurança pública brasileira, cujo objetivo era articular ações de repressão e prevenção à criminalidade no país. Para dar apoio financeiro ao PNSP, foi instituído, no mesmo ano, o Fundo Nacional de Segurança Pública (FNSP). Entretanto, esses avanços na formatação da política de segurança pública não produziram os resultados concretos esperados. De acordo com Fernando Salla,

[...] o Plano Nacional de Segurança Pública [...] compreendia 124 ações distribuídas em 15 compromissos que estavam voltadas para áreas diversas como o combate ao narcotráfico e ao crime organizado; o desarmamento; a capacitação profissional; e o reaparelhamento das polícias, a atualização da legislação sobre segurança pública, a redução da violência urbana e o aperfeiçoamento do sistema penitenciário. Uma novidade é que no plano, além dessas iniciativas na área específica de segurança, eram propostas diversas ações na esfera das políticas sociais. O plano, no entanto, não fixava os recursos nem as metas para ações. Ao mesmo tempo, não estavam estabelecidos quais seriam os mecanismos de gestão, acompanhamento e avaliação do plano (SALLA, 2003, p. 430).

Nessa concepção, o PNSP possibilitou a institucionalização de significativos encaminhamentos de diretrizes para ações de gestão, porém poucos avanços práticos. Sem recursos definidos, sem delineamento de metas e de processos de avaliação de eficácia, eficiência e efetividade, fracassou nos seus principais objetivos. Entretanto, pela primeira vez, após o processo de democratização, emergiu a possibilidade de uma reorientação estratégica, com tratamento político-administrativo direcionado a colocar a questão da segurança pública como política prioritária de governo.

Evidentemente, os avanços foram extremamente tímidos frente à complexidade do problema da segurança pública, tanto que o fenômeno da violência continuou assustando a população brasileira, principalmente nos grandes centros, como têm demonstrado os índices oficiais de criminalidade, diversos estudos e o cotidiano midiático.

As políticas públicas de segurança, justiça e penitenciárias não têm contido o crescimento dos crimes, das graves violações dos direitos humanos e da violência em geral. A despeito das pressões sociais e das mudanças estimuladas por investimentos promovidos pelos governos estaduais e federal, em recursos materiais e humanos e na renovação das diretrizes institucionais que orientam as agências responsáveis pelo controle da ordem pública, os resultados ainda parecem tímidos e pouco visíveis (ADORNO, 2002, p. 8).

As questões relacionadas à segurança pública não podem ser tratadas como política limitada de governo, mas como um processo amplo e complexo a ser enfrentado tanto pelo Estado quanto pela sociedade. Na perspectiva de uma política de Estado, a política de segurança pública, para ser exitosa, não pode dispensar a participação e a contribuição da sociedade. A democratização de toda e qualquer política pública é crucial para atender aos anseios da população.

Tanto o PNSP do governo Fernando Henrique Cardoso, quanto a política de segurança pública emprendida pelo primeiro governo do presidente Luiz Inácio Lula da Silva não tiveram os resultados esperados. Assim, a partir do ano 2007, já no segundo mandato do presidente Lula, foi apresentado um novo programa na área da segurança pública, o Pronasci.

\section{O Programa Nacional de Segurança Pública com Cidadania}

A política de segurança pública implantada pelo governo Lula surgiu em 2001, a partir da elaboração, por parte da ONG Instituto da Cidadania, do Projeto de Segurança Pública para o Brasil, que serviu de base para o programa de governo durante a disputa eleitoral em 2002. A ideia primordial era reformar as instituições da segurança pública e implantar o Sistema Único de Segurança Pública (SUSP) para atuar de forma articulada, por meio de políticas preventivas, principalmente voltadas para a juventude (LOPES, 2009, p. 75). 
A política de segurança pública, consubstanciada a partir do processo de implantação do SUSP, com o objetivo de controle e redução da violência e da criminalidade, estabeleceu o planejamento de ações integradas por parte de órgãos da segurança pública sem, entretanto, considerar o sistema prisional em seu contexto.

O Ministério da Justiça destaca como órgãos executivos da segurança pública as instituições policiais inseridas no artigo 144 da Constituição Federal (BRASIL, 2002). Não define constitucionalmente a existência de uma instituição policial civil como órgão incumbido de gerir o sistema prisional, o que acaba colocando-o à margem do contexto da segurança pública, implicando assim, na fragmentação da política. O Relatório de Gestão da Senasp (BRASIL, 2006, online), exercício de 2006, referente ao período de 2003 a 2006, comprova esta realidade ao relacionar as ações para reestruturar e integrar as diversas organizações programadas na implantação do SUSP:

Modernização Organizacional das Instituições do Sistema de Segurança Pública (Implantação da Segurança Cidadã). Sistema Integrado de Formação e Valorização Profissional. Implantação e Modernização de Estruturas Físicas de Unidades Funcionais de Segurança Pública. Apoio à Implantação de Projetos de Prevenção da Violência. Implantação do Sistema Nacional de Gestão do Conhecimento e de Informações Criminais. Reaparelhamento das Instituições de Segurança Pública. Apoio à Repressão Qualificada. Força Nacional de Segurança Pública.

É possível observar, de acordo com o Relatório, que os eixos de ações destacados pela Senasp querem indicar a ideia de integração dos órgãos e das ações voltadas para a segurança pública, no âmbito de implantação do SUSP, mas apresentam certas limitações e contradições, pois não tornam evidente a inclusão da esfera prisional. Estabelecer ações integradas no campo da segurança pública sem que o sistema prisional, receptor dos resultados de ações policiais ou judiciais, dominado em alguns estados pelo crime organizado, esteja contemplado, significa limitar as possibilidades de atuação coordenada, tanto de forma vertical quanto horizontal. Nesse contexto, as questões relacionadas à situação prisional não podem ser pensadas e trabalhadas de forma deslocada dessa realidade, tendo em vista que as ações, voltadas para o enfrentamento da violência e da criminalidade, ao culminarem com a prisão, impõem a questão do cumprimento da pena na lógica estrutural do sistema de segurança pública.

Buscando a integração nas ações, voltadas para a segurança pública, praticadas pelo Estado brasileiro a partir do ano 2007, o Governo Federal instituiu o Programa Nacional de Segurança Pública com Ci- dadania (Pronasci), em parceria com estados da federação, combinando essas ações com políticas sociais para a prevenção, controle e repressão à criminalidade, principalmente em áreas metropolitanas com altos índices de violência. Nessa perspectiva, estabeleceram-se metas e investimentos que apontam avanços na constituição da política pública de reestruturação do sistema de segurança no seu todo, incluindo-se aí a esfera prisional, redefinindo as estratégias de ação e gestão. No âmbito do Pronasci, surge o conceito de segurança cidadã, o qual

[...] parte da natureza multicausal da violência e, nesse sentido, defende a atuação tanto no espectro do controle como na esfera da prevenção, por meio de políticas públicas integradas no âmbito local. Dessa forma, uma política pública de Segurança Cidadã envolve várias dimensões, reconhecendo a multicausalidade da violência e a heterogeneidade de suas manifestações (FREIRE, 2009, p. 105-106).

Com efeito, o Pronasci apresenta uma forma e um olhar multidisciplinar em relação à questão da segurança pública. Dessa maneira, pela primeira vez após a promulgação da atual Constituição, surge a perspectiva de democratização da política de segurança pública, com efetiva possibilidade de exercício da cidadania por parte da sociedade nesse processo. Seguramente, trata-se de uma mudança complexa no paradigma da segurança, entretanto necessária ao fortalecimento da democracia, pois, "[...] na perspectiva de Segurança Cidadã, o foco é o cidadão e, nesse sentido, a violência é percebida como os fatores que ameaçam o gozo pleno de sua cidadania" (FREIRE, 2009, p. 107). Além disso,

A perspectiva de Segurança Cidadã defende uma abordagem multidisciplinar para fazer frente à natureza multicausal da violência, na qual políticas públicas multissetoriais são implementadas de forma integrada, com foco na prevenção à violência. Nesse sentido, uma política pública de Segurança Cidadã deve contar não apenas com a atuação das forças policiais, sendo reservado também um espaço importante para as diversas políticas setoriais, como educação, saúde, esporte, cultura, etc. (FREIRE, 2009, p. 107).

Com isso, o Pronasci representa uma iniciativa inovadora no trato com a questão da segurança pública, do enfrentamento da violência e da criminalidade, já que busca desenvolver ações na área de segurança integrada com ações sociais, incluindo, acertadamente, o sistema prisional. De acordo com o Ministério da Justiça, o Pronasci “[...] articula políticas de segurança com ações sociais; prioriza a prevenção e busca 
atingir as causas que levam à violência, sem abrir mão das estratégias de ordenamento social e segurança pública" (BRASIL, 2009, online). Isto representa a possibilidade de tornar a política de segurança pública perene, articulada e consistente, e não, apenas, mais uma política de governo pontual.

Em sua estrutura, o Pronasci apresenta-se como uma política de segurança pública, baseada em princípios democráticos, interdisciplinares e humanitários, tendo em vista a participação da sociedade na construção de uma cultura de paz, a médio e a longo prazo. Adota um conjunto de medidas que objetivam a imediata diminuição da violência e da criminalidade, por meio da implementação de Unidades de Polícia Pacificadora (UPPs) em áreas urbanas consideradas de elevados índices de criminalidade e violência. Deve-se ressaltar que a ocupação dessas áreas pela polícia e a instalação das UPPs indica o reconhecimento, por parte do Estado, da necessidade de reorientação estratégica das ações de controle e manutenção da ordem pública. Isso contribui para diminuir os índices de criminalidade, porém, de forma territorialmente limitada. $\mathrm{Na}$ verdade, as UPPs significam a possibilidade de retomada de controle territorial de forma autoritária, porém não necessariamente truculenta. Além disso, podem servir de instrumento tanto ao confinamento da pobreza, quanto ao exercício de direitos básicos de cidadania.

No contexto do Pronasci, a segurança pública tem sido discutida nos mais diversos segmentos da sociedade. No ano de 2009, o Governo Federal promoveu a $1^{\mathrm{a}}$ Conferência Nacional de Segurança Pública (Conseg). Partindo de conferências realizadas nos âmbitos municipal, estadual e de conferências livres organizadas por entidades da sociedade civil, a Conseg representou a possibilidade de se reelaborar, democraticamente, princípios e diretrizes fundamentais para desenvolver projetos voltados para o sistema de segurança pública, sob todos os aspectos e escalas. Por considerarem os contextos locais e o nacional, a efetiva participação de trabalhadores e da sociedade civil, possibilitaram a interação e a interdisciplinaridade no desenho da política. A $1^{\text {a }}$ Conseg (BRASIL, 2009, online) teve como eixos básicos de discussão:

Gestão democrática: controle social e externo, integração e federalismo; financiamento e gestão da política de segurança; valorização profissional e otimização das condições de trabalho; repressão qualificada da criminalidade; prevenção social dos crimes e das violências e construção da cultura de paz; diretrizes para o sistema penitenciário e diretrizes para o sistema de prevenção, atendimentos emergenciais e acidentes.

O espaço de socialização de ideias possibilitado pela $1^{a}$ Conseg, envolvendo a participação da sociedade por meio de suas entidades representativas, elevou e ampliou o debate acerca da política de segurança pública, possibilitando a democratização da política.

Como resultado da $1^{\mathrm{a}}$ Conseg, foram escolhidos, de forma democrática, 10 princípios e 40 diretrizes, que servirão de subsídios para nortear a política de segurança pública em curso no país. Os participantes definiram (BRASIL, 2009a, online) como princípios que a política de segurança pública deve:

\begin{abstract}
Ser uma política de Estado que proporcione a autonomia administrativa, financeira, orçamentária e funcional das instituições envolvidas, nos três níveis de governo, com descentralização e integração sistêmica do processo de gestão democrática, transparência na publicidade dos dados e consolidação do Sistema Único de Segurança Pública (SUSP) e do Programa Nacional de Segurança Pública com Cidadania (Pronasci), com percentual mínimo definido em lei e assegurando as reformas necessárias ao modelo vigente.
\end{abstract}

A definição da política de segurança pública como uma política de Estado, e não de governo, demonstra que a participação da sociedade é essencial no processo político de formulação da política. Pode-se considerar que os avanços teóricos na constituição da política são inegáveis, cabendo-nos, então, aguardar os seus resultados práticos.

Entretanto, como se sabe, os princípios e diretrizes definidos na $1^{\mathrm{a}}$ Conseg não garantem, de imediato, a sua implementação. Caberá à sociedade acompanhar, reivindicar e físcalizar as ações político-administrativas, por meio de seus órgãos representativos, para que a questão não fique somente no âmbito do debate. Portanto, a participação de representantes da sociedade civil, de trabalhadores de todas as áreas, no processo de formatação da política de segurança pública, significa a oportunidade de garantila e de torná-la controlada pela sociedade, em vez de apenas instrumento do Estado.

Nesta última década, a questão da segurança pública tem envolvido uma participação maior de estudiosos, como é o caso da criação do Fórum Brasileiro de Segurança Pública (FBSP), no ano de 2006, composto por vários especialistas com o objetivo de difundir conhecimentos na área da segurança pública. Além disso, o processo de implementação das ações do Pronasci e a ampliação das discussões decorrentes da $1^{\mathrm{a}}$ Conseg resultaram na reestruturação do Conselho Nacional de Segurança Pública (Conasp). São indicadores da ampliação dos espaços de discussão para possibilitar avanços significativos na constituição da política de segurança pública no Brasil contemporâneo, apesar dos limites estruturais. 


\section{Conclusão}

Inegavelmente, a Constituição Federal de 1988 marcou a institucionalização de um novo arcabouço organizacional e administrativo dos órgãos incumbidos da segurança pública no país. Entretanto, os resquícios do período ditatorial permaneceram encravados nas práticas policiais. Além disso, a política de segurança pública, mesmo após o processo de redemocratização, foi imposta pelos governos visando o atendimento de situações imediatistas. Apresentase desconstituída de continuidade, desarticulada entre as instituições e esferas de poder e sem a devida participação da sociedade na definição e estruturação das ações.

As intervenções estatais, em relação à segurança pública no Brasil, tornaram-se mais sistemáticas nesta primeira década do século 21 , quando se configurou a gestão de planos e programas pautados em novas formas de abordar a questão. O PNSP, de 2000, apesar de ter sido um avanço teórico considerável no trato com a questão da segurança pública, enfrentou limites práticos consideráveis no âmbito da gestão, fracassando nos seus objetivos principais.

No entanto, o processo de implantação do SUSP demonstra que a política de segurança pública do país tem sido trabalhada sob o âmbito de um novo paradigma. O Pronasci, de 2007, aponta para a participação da sociedade civil no processo de formatação e implementação da política de segurança pública no país. Ainda é relativamente cedo para se avaliar os resultados do Pronasci quanto à diminuição da criminalidade e da violência. Entretanto, o reconhecimento governamental e institucional em relação à efetiva participação da sociedade na construção da política de segurança pública evidencia um processo de fortalecimento da democracia, imprescindível à efetivação de uma segurança cidadã.

A instituição do Fórum Brasileiro de Segurança Pública, em 2006, e a participação da sociedade civil nos eventos correlacionados à Conseg, realizada em 2009, evidenciam a importância da democracia para a construção de uma política de segurança pública que assegure os direitos de cidadania. Os princípios e as diretrizes elaborados, desde então, demonstram que as expectativas da sociedade, pela participação democrática na gestão da política de segurança pública, estão sendo contempladas.

Os esforços adotados pelos diversos governos e pela sociedade a partir de 2009, por meio de discussões em conferências públicas, credenciando a participação da sociedade na construção de princípios e diretrizes norteadores da política de segurança pública, indicam a possibilidade de consolidação de uma política de Estado que entenda a segurança pública como uma questão transversal e multifacetada. Porém, as ações entre os órgãos da área da segurança pública enfrentam limitações de atuação articulada nas estruturas de poder. O Poder Executivo e o Judiciário não atuam de forma conjunta no sentido de garantir a prevenção do delito, o julgamento célere para evitar, inclusive, a impunidade e a injustiça. Por outro lado, a reinserção do homem preso na sociedade tem sido um dos maiores desafios a serem enfrentados pelo Estado e pela sociedade.

Diante destas considerações, deve-se acrescentar que o processo de estruturação da política de segurança pública exige rupturas, mudanças de paradigmas, sistematização de ações pontuais combinadas a programas consistentes e duradouros fincados, sobretudo, na valorização do ser humano sob todos os aspectos, levando em consideração os contextos sociais de cada cidadão. Os avanços na consolidação de uma política de segurança pública de Estado no Brasil, pautada em princípios democráticos, de solidariedade e dignidade do ser humano indicam que os desafios a serem superados tornam indispensável o exercício da cidadania com fulcro nos direitos de igualdade e na justiça social.

\section{Referências}

ADORNO, S. A gestão urbana do medo e da insegurança: violência, crime e justiça penal na sociedade brasileira contemporânea. 282 p. Tese (apresentada como exigência parcial para o Concurso de Livre-Docência em Ciências Humanas) - Departamento de Sociologia, da Faculdade de Filosofia, Letras e Ciências Humanas da Universidade de São Paulo, 1996. 
. Crime e violência na sociedade brasileira contemporânea. Jornal de Psicologia-PSI, n. Abril/Junho, p. 7-8, 2002.

BENGOCHEA, J. L. et al. A transição de uma polícia de controle para uma polícia cidadã. Revista São Paulo em Perspectiva, v. 18, n. 1, p. 119-131, 2004.

BRASIL. Constituição da República Federativa do Brasil: promulgada em 5 de outubro de 1988. São Paulo: Saraiva, 2002.

Ministério da Justiça. Programa Nacional de Segurança Pública com Cidadania (Pronasci). Disponível em: 〈http://www.mj.gov.br.pronasci> . Acesso em: 29 set. 2009.

Secretaria Nacional de Segurança Pública. Relatório de Gestão. Exercício 2006. Disponível em: <http:/ /www.mj.gov.br.senasp>. Acesso em: 29 set. 2009.

$1^{a}$ Conferência Nacional de Segurança Pública (Conseg). 2009a. Disponível em: <http:// www.mj.gov.br.conseg>. Acesso em: 29 set. 2009.

FARAH, M. F. dos S. Parcerias, novos arranjos institucionais e políticas públicas no nível local de governo. In: FERRAREZI, E.; SARAIVA, E. (Org.). Políticas públicas, Brasília: ENAP, 2006. (Coletânea, v. 2).

FREIRE, M. D. Paradigmas de segurança no Brasil: da ditadura aos nossos dias. Revista Brasileira de Segurança Pública, Ano 3, edição 5, p. 100-114, ago./set. 2009.

LOPES, E. Política e segurança pública: uma vontade de sujeição. Rio de Janeiro: Contraponto, 2009.

PASSETTI, E. Anarquismos e sociedade de controle. São Paulo: Cortez, 2003.

PEREIRA, P. A. P. Discussões conceituais sobre política social como política pública e de direito de cidadania. In: BOSCHETTI, I. (Org.). Política social no capitalismo: tendências contemporâneas. São Paulo: Cortez, 2009.

SALLA, F. Os impasses da democracia brasileira: o balanço de uma década de políticas para as prisões no Brasil. Revista Lusotopie, Paris, v. 10, p. 419-435, 2003.

SAPORI, L. F. Segurança pública no Brasil: desafios e perspectivas. Rio de Janeiro: Editora FGV, 2007.

WACQUANT, L. As prisões da miséria. Tradução de André Telles. Rio de Janeiro: Jorge Zahar Ed., 2001.
Vilobaldo Adelídio de Carvalho

vilobaldogeopp@yahoo.com.br

Agente penitenciário da Secretaria da Justiça do Estado do Piauí

Mestre em Políticas Públicas pelo Programa de PósGraduação em Políticas Públicas da Universidade Federal do Piauí (UFPI)

\section{Maria do Rosário de Fátima e Silva}

rosafat@uol.com.br

Doutorado em Serviço Social pela Pontifícia Universidade Católica de São Paulo (PUC/SP)

Professora Associada no Departamento de Serviço Social e no Programa de Pós-Graduação em Políticas Públicas da UFPI

\section{UFPI - Programa de Pós-Graduação em Políti-} cas Públicas

Campus Universitário Ministro Petrônio Portela

Bairro Ininga

Teresina - Piauí

CEP: 88036-601 